\title{
Highly Polarized HLA Class II Antigen Processing and Presentation by Human Intestinal Epithelial Cells
}

\author{
Robert M. Hershberg, ${ }^{\ddagger}$ Diane H. Cho, ${ }^{\star}$ Adel Youakim, " M. Brigid Bradley, " Janet S. Lee," Paul E. Framson, ${ }^{\star}$ \\ and Gerald T. Nepom§ \\ $*$ Virginia Mason Research Center, Seattle, Washington 98101; ${ }^{\ddagger}$ Division of Medical Genetics, and ${ }^{\S}$ Department of Immunology, University \\ of Washington School of Medicine, Seattle, Washington 98195; "Immunex Corporation, Seattle, Washington 98101; and IImmunology \\ Program, Memorial Sloan Kettering Cancer Center, New York 10021
}

\begin{abstract}
The high concentration of foreign antigen in the lumen of the gastrointestinal tract is separated from the underlying lymphocytes by a single cell layer of polarized epithelium. Intestinal epithelial cells can express HLA class II antigens and may function as antigen-presenting cells to $\mathrm{CD}^{+} \mathrm{T}$ cells within the intestinal mucosa. Using tetanus toxoid specific and HLA-DR-restricted T lymphocytes, we show that polarized intestinal epithelial cells directed to express HLADR molecules are able to initiate class II processing only after internalization of antigen from their apical surface. Coexpression of the class II transactivator CIITA in these cells, which stimulates highly efficient class II processing without the characteristic decline in barrier function seen in polarized monolayers treated with the proinflammatory cytokine $\gamma$-IFN, facilitates antigen processing from the basolateral surface. In both cases, peptide presentation to $T$ cells via class II molecules was restricted to the basolateral surface. These data indicate a highly polarized functional architecture for antigen processing and presentation by intestinal epithelial cells, and suggest that the functional outcome of antigen processing by the intestinal epithelium is both dependent on the cellular surface at which the foreign antigen is internalized and by the underlying degree of mucosal inflammation. (J. Clin. Invest. 1998. 102:792-803.) Key words: intestinal epithelium $•$ HLA class II • cell polarity $\bullet$ oral tolerance $\bullet$ inflammatory bowel disease
\end{abstract}

\section{Introduction}

The intestinal epithelium is composed of polarized epithelial cells that provide a crucial barrier function. This single cell layer separates a myriad of bacterial and food antigens in the lumen of the gastrointestinal tract from the largest complement of lymphocytes in the body, which defines the gut-associ-

Address correspondence to Robert M. Hershberg, Virginia Mason Research Center, 1000 Seneca Street, Seattle, WA 98101. Phone: 206583-6525; FAX: 206-223-7543; E-mail: hersh@u.washington.edu

Received for publication 24 February 1998 and accepted in revised form 11 June 1998.

J. Clin. Invest.

(C) The American Society for Clinical Investigation, Inc. 0021-9738/98/08/0792/12 \$2.00

Volume 102, Number 4, August 1998, 792-803

http://www.jci.org ated lymphoid tissue (GALT) ${ }^{1}$ In addition to its crucial role in barrier function and in nutrient and ion transport, the intestinal epithelium is an active component in the complex immunoregulation of the GALT. Intestinal epithelial cells (IECs) secrete a wide variety of cytokines, both constitutively and after invasion with bacterial pathogens (1). Moreover, IECs have extensive cellular contact with several distinct populations of $\mathrm{T}$ lymphocytes both within the epithelium (intestinal epithelial lymphocytes) and in the underlying lamina propria (lamina propria lymphocytes). Whereas several molecules that mediate the physical interaction between $\mathrm{T}$ cells and intestinal epithelial cells have been identified (2), the functional consequences of these interactions are not well understood.

Recent studies in experimental systems of both oral tolerance (3-5) and inflammatory bowel disease (6) have underscored the importance of mucosal $\mathrm{CD}^{+}$lymphocyte responses. Because the surface expression of class II molecules is essential in cells capable of functioning as antigen-presenting cells (APCs) to $\mathrm{CD}^{+}{ }^{+} \mathrm{T}$ cells (7), it is noteworthy that numerous reports have described the low level of HLA class II antigens on the surface of normal IEC and the increased expression of these molecules in a variety of pathological conditions, including inflammatory bowel disease (8), graft-versus-host disease (9), and Celiac disease (10). The cellular machinery for efficient processing and presentation of antigen to $\mathrm{CD}^{+} \mathrm{T}$ lymphocytes via HLA class II includes a variety of cellular proteases, as well as the invariant chain (Ii) and HLA-DM heterodimer (reviewed in references 11 and 12). Indeed, Kaiserlian et al. have shown that murine IECs can function as APCs to $\mathrm{CD}^{+}$cells (13). We have recently characterized the class II pathway in several human IEC lines, and shown that these cells can process and present antigen to $\mathrm{CD}^{+} \mathrm{T}$ cells in a pathway modulated by the expression of Ii and HLA-DM (14).

An important issue arises when considering the in vivo APC function of IECs due to the tight junctions that restrict the passage of macromolecules between individual cells. Specifically, the apical (or luminal) surface of the IEC is selectively exposed to high concentrations of foreign antigen; yet, the expression of HLA class II antigens on epithelial cells in tissue sections of intestinal mucosa from human $(15,16)$ and rat (17) was observed to be restricted to the basolateral surface. The situation is not static, however, because in the presence of inflammatory cytokines such as $\gamma$-interferon $(\gamma$-IFN),

1. Abbreviations used in this paper: APC, antigen-presenting cell; CIITA, class II transactivator; GALT, gut-associated lymphoid tissue; HRP, horseradish peroxidase; IEC, intestinal epithelial cell; Ii, invariant chain; MDCK, Madine-Darby canine kidney; TER, transepithelial resistance; TT, tetanus toxoid. 
the barrier function of the epithelium is significantly impaired (18). The resulting increase in paracellular transport of luminal antigens would result in the concurrent exposure of both the apical and basolateral surfaces of the cell to foreign antigens. In this regard, differences in the cellular trafficking of antigen after exposure to either the apical or basolateral surfaces of polarized, HLA class II positive epithelial cells may have functional consequences in the regulation of the adjacent and subjacent T lymphocytes. Conceivably, these differences might tilt the delicate balance in the GALT away from immune tolerance towards the inflammatory response seen in the intestinal mucosa in a wide variety of clinical disorders.

Here we describe a model system to study the physiologic interaction between polarized epithelial cells and $\mathrm{CD}^{+} \mathrm{T}$ lymphocytes, and investigate the polar nature of HLA class II antigen processing and presentation by IECs. Using the polarized human IEC line T84 engineered to constitutively express HLA-DR molecules, we demonstrate the restricted expression of HLA class II antigens at the basolateral surface of the cell, mimicking the topologically restricted expression pattern seen in vivo. Using tetanus toxoid specific and HLA-DR-restricted $\mathrm{T}$ cells, we demonstrate that, in the absence of Ii and HLADM, only exposure of antigen at the apical surface of the T84 HLA-DR transfectants is capable of initiating HLA class II processing and presentation. However, when the T84 HLADR transfectants are engineered to also overexpress the class II transactivator (CIITA), resulting in the induced expression of invariant chain and HLA-DM, both the apical and basolateral surface can initiate processing. These data are consistent with a model in which both the polarized exposure of antigen and the underlying level of mucosal inflammation may dramatically modulate the functional outcome of the class II antigen processing by the intestinal epithelium.

\section{Methods}

Cells and transfectants. The T84 cell line (ATCC CCL-248) was determined by reverse dot blot hybridization with HLA-DR-specific probes to be: DRB1*0101/09012 and DRB4*0101. HLA-DRB1*0401expressing transfectants were generated by retroviral infection as previously described (14). Where indicated, the T84 HLA-DR transfectants were superinfected with a recombinant retrovirus expressing the class II transactivator, CIITA (19). Dividing T84 HLA-DRB1*0401 transfectants were exposed to fresh recombinant CIITA virus daily for $7 \mathrm{~d}$ and infection was verified as described in Results. T84 cells were grown in DME supplemented with $10 \%$ vol/vol FBS, non-essential amino acids (GIBCO BRL, Gaithersburg, MD), $20 \mathrm{mM}$ glutamine, and penicillin/streptomycin. The EBV-transformed B-LCL BSM and the $\mathrm{B} \times \mathrm{T}$ hybrid $\mathrm{T} 2$ (containing a homozygous deletion of the HLA class II locus including the region encoding HLA-DM) were grown in RPMI with $10 \% \mathrm{vol} / \mathrm{vol} \mathrm{FBS}$ and $50 \mathrm{mM} \beta$-mercaptoethanol.

Confocal microscopy. Cells were grown on borosilicate chamber coverslips (Lab-Tek, Nunc, Napierville, IL) or on polycarbonate filter inserts (6.5 mm diameter, $0.4 \mu$ pore size; Costar, Cambridge, MA) and maintained for 3-5 d after confluence (transepithelial resistance [TER] $>1,000 \mathrm{ohms} \mathrm{cm}^{2}$ ). Processing of the cells for immunofluorescence was done at room temperature. Cells were washed three times with PBS, fixed for $15 \mathrm{~min}$ in $4 \%$ paraformaldehyde in PBS, washed twice in PBS, and incubated for $30 \mathrm{~min}$ in $50 \mathrm{mM} \mathrm{NH}_{4} \mathrm{Cl}$ to quench unreacted aldehyde groups. The cells were washed twice more with PBS and then permeabilized and blocked in PBS containing $0.1 \%$ Triton X-100 and 5\% BSA (PTB) for $30 \mathrm{~min}$. Subsequently, the cells were incubated with primary antibodies (anti-E-cadherin and antiZO-1; Zymed Laboratories, San Francisco, CA); anti-HLA class I
(W6/32, kindly provided by Daniel Geraghty, Fred Hutchinson Cancer Research Center, Seattle, WA); anti-HLA-DR (L243), diluted in PTB for 1-2 h, washed three times with PBS, and then incubated for $1 \mathrm{~h}$ with the appropriate fluorescent-conjugated secondary antibody (Oregon green goat anti-rabbit IgG for the anti-ZO-1 antibody, and Rhodamine goat anti-mouse IgG for the others; Molecular Probes, Eugene, OR) diluted in PTB. After washing with PBS three times, the coverslips or filters (cut out of their holders and placed on slides) were mounted and then covered with $\mathrm{DABCO} /$ glycerol/PBS, and in the case of the filters, coverslipped and sealed before microscopy. The samples were analyzed by on a Molecular Dynamics Laser Scanning Microscope Model 2001 (Molecular Dynamics, Sunnyvale, CA) equipped with an $\mathrm{Kr} / \mathrm{Ar}$ laser and a Nikon $60 \times$ NA 1.4 oil lens. Images were collected using an SGI Iris Indigo 4000 Workstation (Silicon Graphics, Mountain View, CA). The final images were prepared using Adobe Photoshop V3.0. All images were processed identically.

Cell surface-specific biotinylation, immunoprecipitation, and immunoblotting. For biotinylation, cells were grown on polycarbonate filter inserts ( $24 \mathrm{~mm}$ diameter, $0.4 \mu$ pore size; Costar, Cambridge, MA) until TER were $>1,000 \mathrm{ohms} \mathrm{cm}^{2}$. The cells were labeled either apically or basolaterally with biotin (Calbiochem, San Diego, CA) as previously described (20). After biotinylation, cells were solubilized in Lysis buffer (2.5\% n-octylglucoside, $0.1 \mathrm{M}$ Tris, $\mathrm{pH}$ 7.4, $0.15 \mathrm{M}$ $\mathrm{NaCl}, 2 \mathrm{mM} \mathrm{MgCl} 2,0.02 \% \mathrm{NaN}_{3}, 1 \mu \mathrm{g} / \mathrm{ml}$ leupeptin, $1 \mu \mathrm{g} / \mathrm{ml}$ pepstatin, and $1 \mathrm{mM} \mathrm{PMSF}$ ) for $90 \mathrm{~min}$ at $4^{\circ} \mathrm{C}$ with frequent titration. The lysates were centrifuged at $14,000 \mathrm{~g}$ for $10 \mathrm{~min}$ and the supernatants retained for immunoprecipitation. $100 \mu \mathrm{g}$ of the supernatants were incubated with $20 \mu \mathrm{g}$ of antibody overnight at $4^{\circ} \mathrm{C} .50$ microliters of Protein $\mathrm{G}$ agarose (prewashed in Lysis buffer containing 5\% BSA) was added to the samples and they were further incubated at $4^{\circ} \mathrm{C}$ for 90 min. The Protein G agarose was washed four times with Lysis buffer and the bound material eluted by boiling for $10 \mathrm{~min}$ in reducing SDS-PAGE sample buffer. The eluted samples were fractionated on a $10 \%$ Tris-glycine gel, transferred to nitrocellulose, blocked overnight in PBS containing $0.1 \%$ Tween 20 and $5 \%$ BSA at $4^{\circ} \mathrm{C}$, and the biotinylated proteins were detected using streptavidin-horseradish peroxide (HRP; Jackson Labs, Bar Harbor, ME) and a chemiluminescent substrate for peroxidase (ECL; Amersham Corp., Arlington Heights, IL) followed by exposure to film.

Immunoblot analyses of invariant chain using the mAb Pin-1 and HLA-DM $\beta$ using anti-HLA-DM $\beta$ rabbit serum (both kindly provided by Peter Cresswell, Yale University, New Haven, CT), and for HLA-DM $\alpha$ using anti-HLA-DM $\alpha$ rabbit serum (kindly provided by Alexander Rudensky, University of Washington, Seattle, WA) were performed using goat anti-mouse or goat anti-rabbit IgG + IgM (Jackson ImmunoResearch Laboratories, Inc.) and chemiluminescence as described (14).

Analysis of barrier function. $300 \times 10^{3}$ T84 cells were plated on upright transwell filters ( $3.0 \mu \mathrm{m}$ pore size; Costar) exposing the apical surface to the top chamber, or on upside down filters that were subsequently inverted exposing the basolateral surface to the top chamber. Cells were cultured until TER exceeded $1,000 \mathrm{ohms} \mathrm{cm}^{2}$ (generally 5-7 d) before use in antigen presentation or processing experiments. TER was assessed using an epithelial voltometer (EVOM, Sarasota, FL) and converted to ohms $\mathrm{cm}^{2}$ based on the surface area of the transwell filter. Bulk protein transport was assessed using intact horseradish peroxidase, as described (21).

$T$ cells and antigen-processing/presentation assays. Antigen-specific, HLA-DRB1*0401-restricted T cell hybridomas were kindly provided by Dennis Zaller (Merck Research Labs., Rahway, NJ). The tetanus toxoid (TT)-specific T cell hybrid 49.23.2, and the HSA-specific T cell hybrid 17.9 were generated after immunization of a DR4w4 transgenic mouse with tetanus or HSA, respectively (22). TT (Wyeth Refined Concentrate, Wyeth-Ayerst, Swiftwater, PA) was extensively dialyzed at $4{ }^{\circ} \mathrm{C}$ against PBS. TT-specific, HLA-DRB $1 * 0401$-restricted human $\mathrm{T}$ cell clones were generated from the peripheral blood of a healthy HLA-DRB1*0401 individual as previously detailed (14). Clonality of the T cells was confirmed by RT-PCR using a panel of 
TCR $\mathrm{V} \alpha$ and $\mathrm{V} \beta$ primers as described (23). Clone 2 was found to use the gene segment encoding V $\beta 5.2$ and clone 4 was found to use the gene segment encoding $\mathrm{V} \beta 13$. For clone 4 , these data were confirmed using a V $\beta 13$ subfamily-specific monoclonal antibody (Endogen, Inc., Cambridge, MA).

For antigen-processing and/or presentation assays, T84 cells were plated on transwells, and the monolayers were verified to have a TER $>1,000 \mathrm{ohms} \mathrm{cm} \mathrm{cm}^{2}$ at the start of the experiment. For the peptide presentation experiments, HSA peptide was added to the top chamber of upright or inverted transwell cultures for $30 \mathrm{~min}$, followed by the addition of $100 \times 10^{3}$ HSA-specific hybridoma cells. Supernatent from the co-culture was collected after $24 \mathrm{~h}$ and assayed for IL-2 using the HT-2 cell line as previously described (14). For the processing experiments, TT was applied to the upper or lower chamber of inverted transwell monolayers as shown in Fig. 4, resulting in basolateral or apical exposure to antigen, respectively. After $4 \mathrm{~h}$, the antigen was removed and $100 \times 10^{3} \mathrm{TT}$-specific $\mathrm{T}$ cell hybridoma or $\mathrm{T}$ cell clones were applied to the top chamber and co-cultured with the T84 cells for $24 \mathrm{~h}$. The supernatant was collected after $24 \mathrm{~h}$ and assayed for IL-2 using HT-2 cells. For the drug experiments, cells were prepulsed with drug from both the apical and basolateral surfaces for $30 \mathrm{~min}$ before adding antigen and the drug was present during antigen pulsing. Drug was removed from both chambers with the removal of antigen. All drugs were purchased from Sigma Chemical Co. (St. Louis, MO).

For the assays with the $\mathrm{T}$ cell clones, the $\mathrm{T}$ cells were removed from the transwells after $24 \mathrm{~h}$, transferred to 96-well flat bottom plates, and cultured for $48 \mathrm{~h}$ in RPMI supplemented with $10 \% \mathrm{vol} / \mathrm{vol}$ FBS without the addition of exogenous IL-2. $1.0 \mu \mathrm{Ci}$ of ${ }^{3}[\mathrm{H}]$-thymidine was present during the final $16 \mathrm{~h}$ of culture, and radiolabeled incorporation was measured by scintillation spectroscopy. $\gamma$-IFN (Genzyme, Cambridge, MA) was prepared and used according to manufacturer's instructions.

\section{Results}

HLA expression is largely restricted to the basolateral surface of polarized T84 cells. The intestinal epithelial cell line T84 forms polarized monolayers in vitro and has been used extensively as a model to investigate a variety of physiologic and immunologic properties of the intestinal epithelium (e.g., 1, 18, 24). To study the HLA class II antigen processing pathway in a manner independent of the cytokines required to induce class II expression in this cell line, we used retroviral-mediated gene transfer to generate T84 cells that constitutively express surface HLA-DR molecules, and demonstrated that these cells could both process and present antigen to $\mathrm{CD}^{+} \mathrm{T}$ lymphocytes (14).

Previous studies addressing the distribution of HLA class II on the intestinal epithelium in vivo have observed the expression of these molecules to be restricted to the basolateral surface (15-17). To determine whether the T84 HLA-DR transfectants would be a suitable model to study polarized aspects of HLA class II antigen processing and presentation, we used confocal microscopy to examine the polarized expression of HLA-DR in these cells. As seen in Fig. 1, the wild-type T84

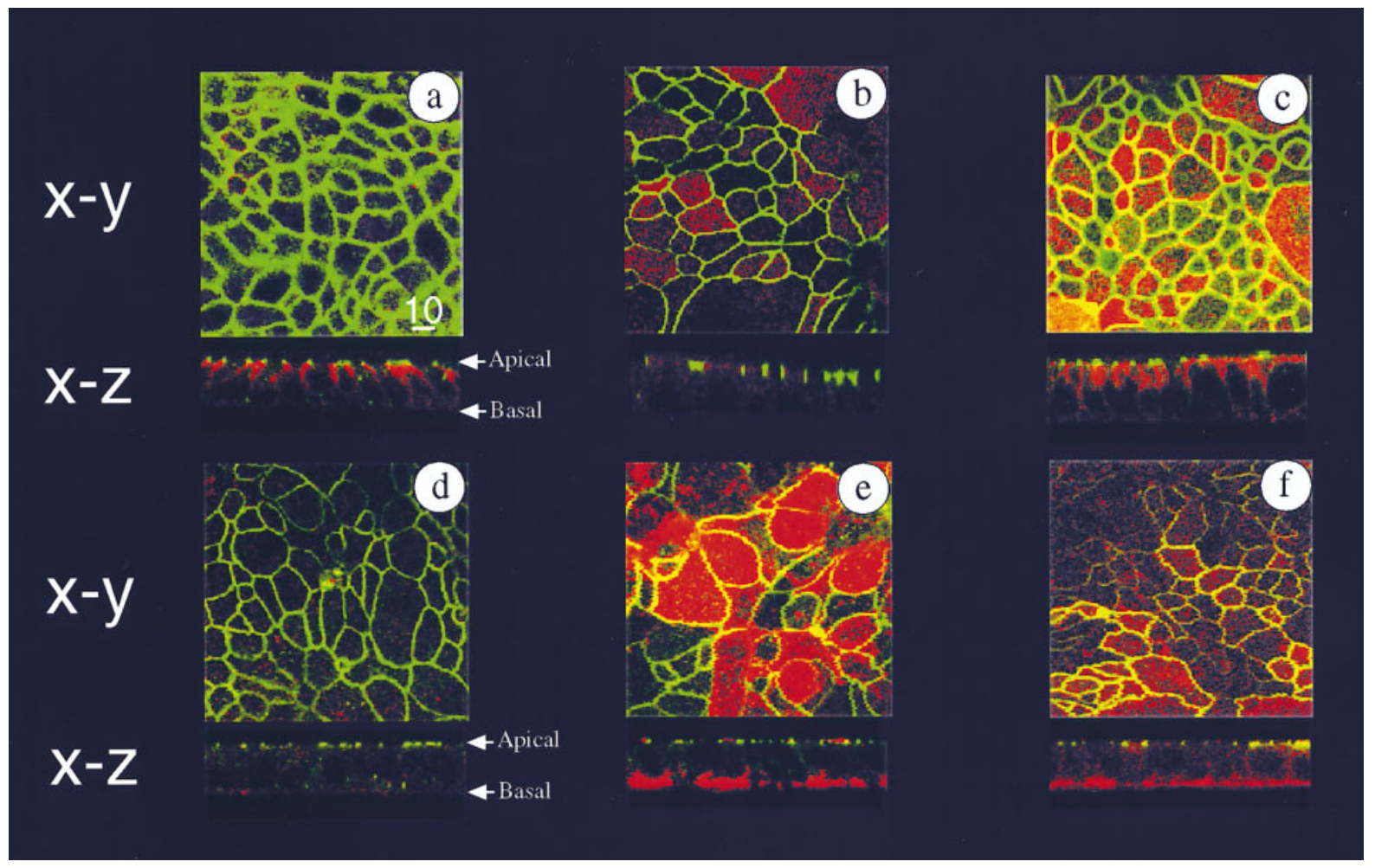

Figure 1. Expression of HLA-DR molecules in polarized T84 cells is restricted to the basolateral surface. Shown are confocal microscopic images of wild-type T84 cells (top, bottom left), T84 HLA-DRB1*0401 (bottom middle), and T84 HLA-DRB1*0401/CIITA transfectants (bottom right $)$ stained with a variety of $\mathrm{mAb}$. Depicted are horizontal $(X-Y$, or en face) images, with representative vertical $(X-Z)$ sections below. In all pictures cells are stained with anti-ZO-1, and secondary antibody for anti-ZO-1 was goat anti-rabbit ${ }^{\text {Oregon green }}$. All other antibodies listed used goat anti-mouse ${ }^{\text {rhodamine }}$ as secondary antibody. Co-staining in $A$ : anti-E cadherin; $B$ : anti-MDR; $C$ : anti-HLA class I; $D-F$ : anti-HLA class II. Cells were grown on transwells until TER $>1,000 \mathrm{ohm} \mathrm{cm}^{2}$, and fixed, permeabilized, and stained with saturating concentrations of antibody as outlined in Methods. Staining with secondary antibodies alone was used to define background staining. 
cells (Fig. 1, $a-d$ ) as well as the T84 HLA-DR transfectants in the absence (Fig. $1 e$ ) or presence (Fig. $1 f$ ) of the directed overexpression of the class II transactivator CIITA (see below) form monolayers that demonstrate the polarized characteristics of a number of proteins and the presence of discrete tight junctions. Specifically, staining with antibodies directed against the tight junction complex molecule ZO-1 was apical and junctional (Fig. 1, $a-f$ ), whereas the staining with an antibody directed against E-cadherin showed the characteristic basolateral pattern, with more staining evident along the lateral aspects of the cell (where it functions in cell adhesion) than along the basal portion of the cell (Fig. $1 a$ ). An identical pattern of E-cadherin staining was seen in the T84 HLA-DR transfectants (data not shown).

Staining with several monoclonal antibodies specific for HLA-DR revealed predominantly basolateral surface staining, with the most prominent staining seen along the basal aspects of the cell (Fig. $1 e$ and $f$ ). As seen in the horizontal X-Y (en face) images, intracellular class II staining was also evident and vesicular in nature (Fig. 1, $e$ and $f$ ). This pattern was not HLADR allele-specific as T84 cells expressing their endogenous HLA-DRB1*0101 allele (either after treatment with $\gamma$-IFN or with directed expression of CIITA alone in the absence of the transfected DR4 allele) showed an identical pattern (data not shown). The staining seen with a monoclonal antibody directed against HLA class I revealed a pattern similar to that seen with antibodies against E-cadherin, with more prominent surface expression along the lateral aspect of the cell and no apical surface expression (Fig. 1c). Less intracellular staining was evident with HLA class I than HLA class II antibodies. The staining with an antibody directed against the P-glycoprotein (MDR1, used as an apical marker) was faint but restricted to the apical surface.

To confirm that the distribution of the various proteins by confocal microscopy was indeed polarized, we used selective cell surface biotinylation to independently assess and quantitate the polarized expression of HLA-DR in the T84 transfectants $(20,25,26)$. The surface of intact, mature monolayers (with TER values $>1,000 \mathrm{ohm} \mathrm{cm}^{2}$ ) were labeled apically or basolaterally with biotin, after which the cells were lysed, immunoprecipitated using antibodies to the specific proteins, analyzed by SDS-PAGE, and transferred to nitrocellulose. The biotinylated proteins were detected using peroxidase-conjugated streptavidin and chemiluminescence.

As seen in Fig. 2, class II expression was only seen on the basolateral surface of the transfected cells, whereas none was seen on the apical surface. The expression of E-cadherin (a well characterized marker of the basolateral surface) and class I were similarly localized. In contrast, MDR1a could only be detected when the cells were biotinylated apically. The lack of surface biotinylation of class II on the apical surface suggests that the small amount of staining seen on the apical aspect of the cells by confocal microscopy represented intracellular pools of the protein. These data indicate that the polarized expression of class II in T84 on the basolateral surface mimics the staining pattern for class II seen in vivo, and neither requires matrix components of the underlying basement membrane nor contact with adjacent (intraepithelial lymphocytes) or subjacent (lamina propia lymphocytes) T lymphocytes.

Antigen presentation to $C D 4^{+} T$ lymphocytes is limited to the basolateral surface, but antigen processing is predominantly initiated from the apical surface in T84 HLA-DR transfec-

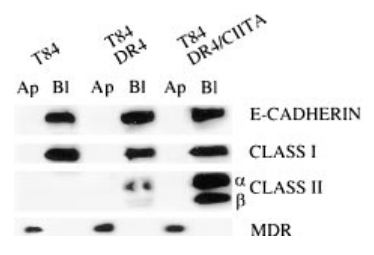

Figure 2. Selective cell surface biotinylation reveals polarized expression of HLA class II molecules at the basolateral surface. T84 wild type, T84 DRB1*0401, and T84 DRB1*0401/CIITA transfectants were plated on transwells until a TER $>1,000 \mathrm{ohm} \mathrm{cm}^{2}$ was ob-

tained, and then biotinylated on their apical or basolateral surface. After lysis in $2.5 \%$ n-octylglucoside, immunoprecipitation was performed using $\mathrm{mAb}$ against the proteins listed, and the samples were fractionated on a $10 \%$ polyacrylamide gel and transferred to nitrocellulose as described. Streptavidin-HRP and the chemiluminscent substrate ECL were used to detect biotinylated protein. E-cadherin and MDR are markers of basolateral and apical membranes, respectively.

tants. To address the question of which surface or surfaces of polarized epithelial cells were capable of stimulating $\mathrm{CD}^{+} \mathrm{T}$ cells, T84 HLA-DRB1*0401 transfectants were grown on semi-permeable transwell filters and tested for their ability to stimulate a peptide-specific, HLA-DRB1*0401-restricted T cell hybridoma. As schematically outlined in Fig. 3, T84 cells were grown with their apical or basolateral surface exposed to the top chamber of the transwell insert, and cultured to allow the formation of a monolayer with intact tight junctions and high electrical resistance $\left(>1,000 \mathrm{ohms} \mathrm{cm}^{2}\right)$. The T84 DR4 cells were pulsed for $1 \mathrm{~h}$ with peptide, after which $\mathrm{T}$ cell hybridomas were added. T cells were always added to the top chamber to maximize IEC-T cell contact. Consistent with the pattern of cell surface expression of class II antigens observed by confocal microscopy and selective surface biotinylation, only the basolateral surface of the T84 cells could present peptide antigen to T lymphocytes (Fig. 3). No stimulation was seen when the peptide and $\mathrm{T}$ cells were added to the apical surface of the T84 DR4 transfectants. The stimulation was HLA-DR allele-specific, as the T84 transfected with HLA-DRB1*1101 (DR5) failed to stimulate the hybridoma.

APCs normally must process intact protein to generate the antigenic peptides that bind to nascent or recycled class II molecules. To determine which surface or surfaces of the enterocyte could initiate antigen processing of an intact protein via HLA class II molecules, we exposed either the apical or basolateral surface of electrically resistant, polarized T84 DRB1*0401 monolayers to an intact protein antigen (TT). As shown in Fig. 3 , because antigen presentation occurred only at the basolateral surface due to the restricted expression of HLA-DR, the T84 transfectants were always plated "bottoms up" with their basolateral surface exposed to the top chamber. Hence, the cells were pulsed with intact antigen by addition to the bottom (apical) or top (basolateral) chamber. Processing was quantitated using a TT-specific, HLA-DRB1*0401-restricted T cell hybridoma, added after antigen pulsing and washing. As shown schematically in Fig. $4 A$, the T cells were always added to the top chamber where basolateral contact (and antigen presentation) occurs. Significant processing occurred only after exposure of the apical surface to antigen at the concentration of $80 \mu \mathrm{g} / \mathrm{ml}$ that we had defined as the optimal concentration from previous work with these transfectants (14) (Fig. 4A). To ensure that the results obtained were not restricted to a single concentration of antigen, we performed dose response curves for apical and basolateral antigen processing. As shown in Fig. $4 \mathrm{~B}$, minimal to no processing was seen when intact antigen 

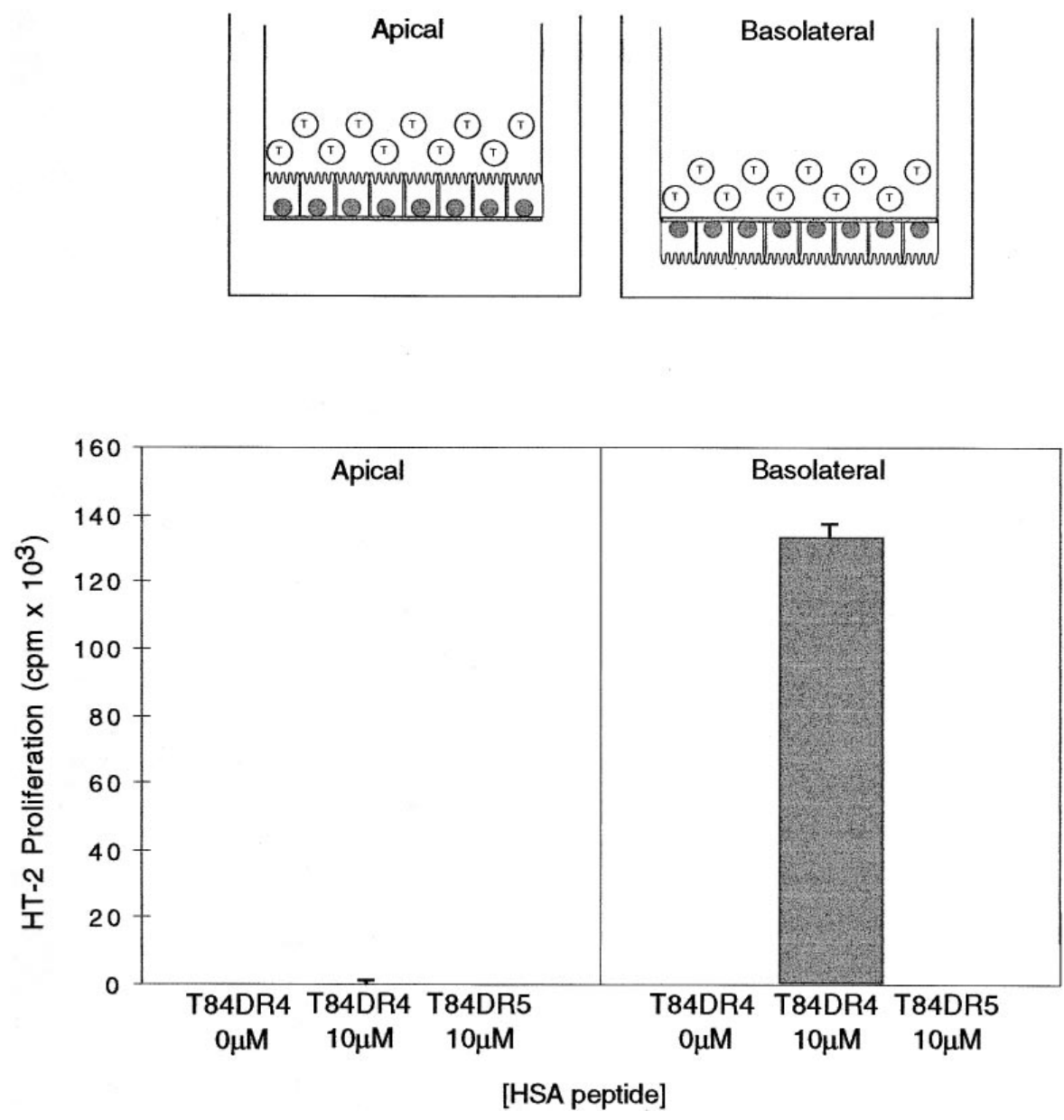

Figure 3. HLA-DR-restricted peptide presentation occurs only at the basolateral surface of T84 cells. (Top) Schematic view of transwell antigen presentation assay. T84 cells are plated on upright transwell filters ( $3.0 \mu$ pore size), exposing the apical surface to the top chamber, or on upsidedown filters that are subsequently inverted, exposing the basolateral surface to the top chamber. T cells are always added to the top chamber to maximize T cell-T84 contact. (Bottom) T84 HLA-DRB1*0401 transfectants plated in the apical or basolateral orientation were co-cultured with HSA-specific, HLA-DRB1*0401restricted T cell hybridoma cells for $24 \mathrm{~h}$ in the absence or presence of $10 \mathrm{mM}$ of the HSA peptide for which the hybridomas are specific. T84 transfectants expressing similar levels of the HLA-DRB1*1101 (DR5) allele were used as a negative control. IL-2 production of the hybridomas was quantitated using the supernatant from the top chamber by $\left[{ }^{3} \mathrm{H}\right]$ thymidine uptake $(\mathrm{cpm})$ of the IL-2/IL-4 dependent T cell line HT-2, as described in Methods. was added to the basolateral surface over a wide range of TT concentrations. As with the peptide-specific presentation seen in Fig. 3, no class II-mediated antigen presentation of processed antigen was seen at the apical surface (data not shown). Note that these observations are consistent with our previous results on 96-well plates (in contrast to the transwell system described here), demonstrating that T84 DR4 are capable of limited class II processing in the absence of Ii and HLA-DM (14).

To ensure that the differences observed did not simply reflect an inability of the basolateral surface of the T84 DR4 cells to internalize protein antigen, we directly measured the uptake of intact HRP by both the apical and basolateral surface at various time points including 15,30, and $60 \mathrm{~min}$. At all time points tested in several independent experiments, the basolateral surface was more efficient at internalizing HRP than the apical surface under identical conditions (data not shown).

Overexpression of the class II transactivator, CIITA, results in efficient antigen processing without affecting the barrier function of polarized T84 cells. We have recently shown that efficient antigen processing by T84 cells requires the expression of not only class II antigens and cellular proteases, but also the Ii and the HLA-DM heterodimer (14). The role of these molecules in class II biosynthesis and antigen processing has been extensively reviewed $(11,12)$. The expression of both Ii and HLA-DM is induced by $\gamma$-IFN in T84, likely mediated by the transcriptional activation of these genes by the CIITA, the expression of which is also induced by $\gamma$-IFN (27).
T84 DRB1*0401 transfectants superinfected with a retrovirus directing the overexpression of CIITA resulted in class II antigen processing and presentation to $\mathrm{CD} 4^{+} \mathrm{T}$ cells similar to that seen after treatment of the cells with $\gamma$-IFN (Fig. $5 A$ ). The induced expression of Ii, HLA-DM $\alpha$ and HLA-DM $\beta$ was confirmed in the T84 CIITA transfectants by immunoblotting (Fig. 5 B). As previously shown (14) and confirmed here, the wild-type T84 cells do not express Ii, HLA-DM $\alpha$, or HLA$\mathrm{DM} \beta$. We also used an HLA-DR1-specific mAb and flow cytometry to demonstrate the expression of the endogenous HLA-DRB1*0101 allele induced by the overexpression of CIITA (data not shown).

In addition to stimulating antigen processing by T84 cells, $\gamma$-IFN treatment has been observed to elicit a profound and relatively rapid decrease in TER in T84 monolayers without an immediate alteration in cell morphology or integrity of the monolayer (18). This alteration in barrier function after $\gamma$-IFN treatment would limit the ability to selectively expose one surface of the cell to intact antigen and to independently study the polarity of antigen processing and presentation. Surprisingly, we observed that the T84 HLA-DRB1*0401 transfectants overexpressing CIITA were able to maintain a high TER (Fig. $5 \mathrm{C}$ ), despite showing many of the characteristics of transfectants treated with $\gamma$-IFN with regards to class II antigen processing. Treatment of the T84 CIITA transfectants with $\gamma$-IFN resulted in the characteristic decline in TER seen in the wildtype T84 cells (Fig. $5 \mathrm{C}$ ), suggesting that the directed overex- 

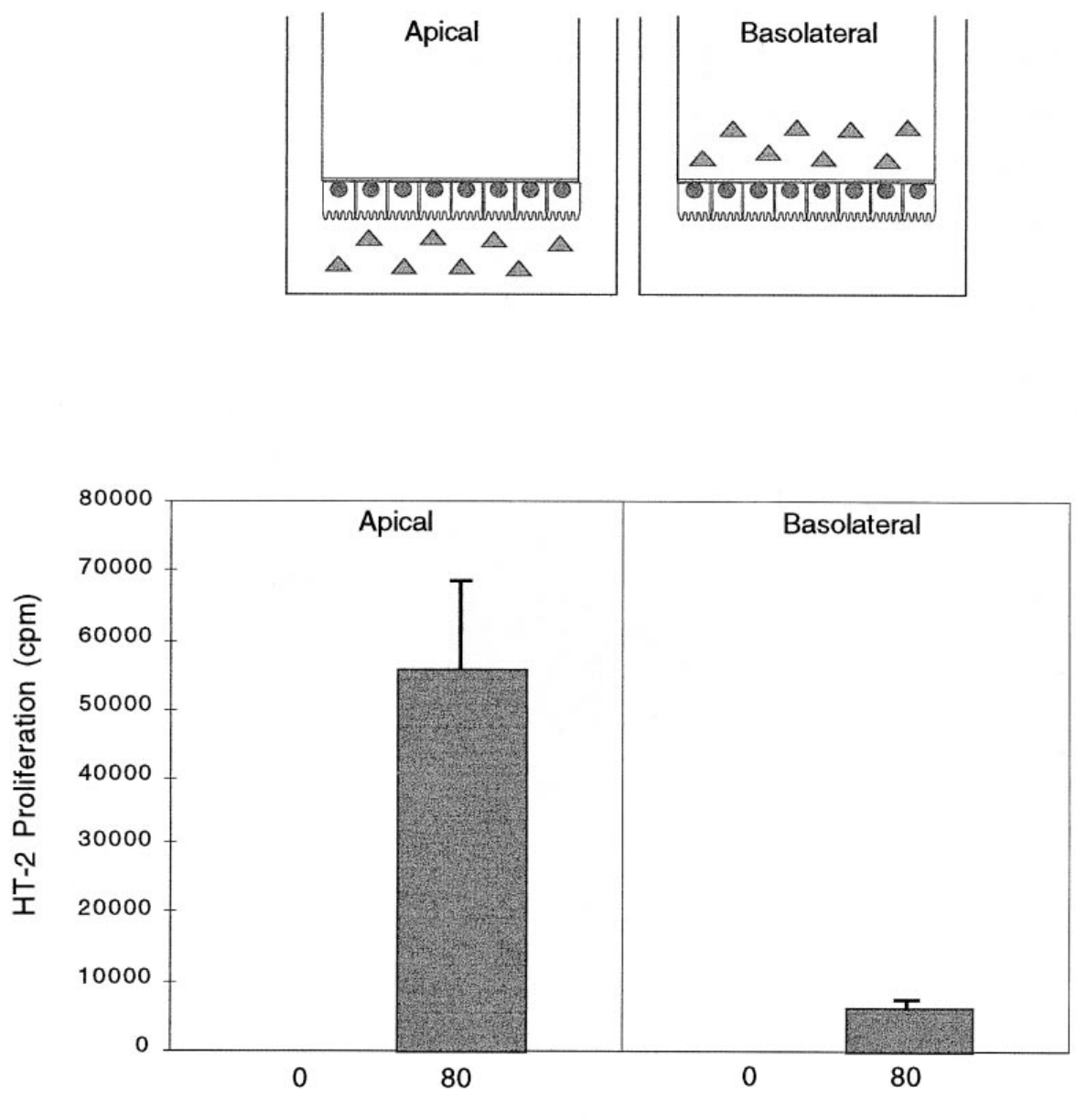

[TT], $\mu \mathrm{g} / \mathrm{ml}$

B

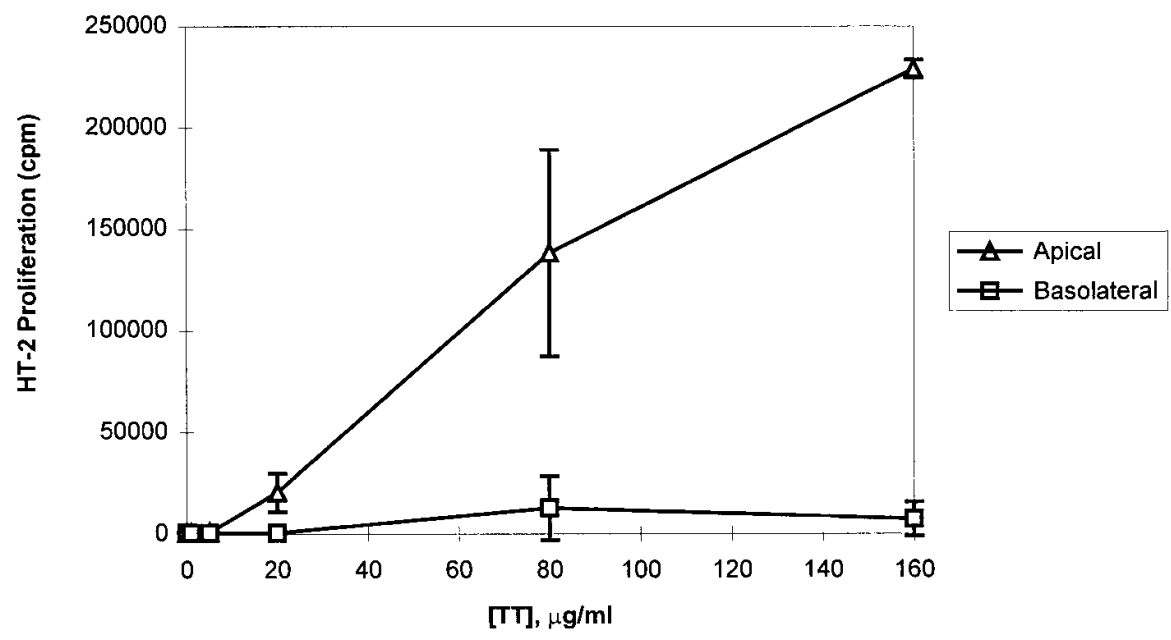

Figure 4. Class II antigen processing of intact tetanus toxoid in T84 HLA-DR transfectant is markedly more efficient after exposure of intact antigen from the apical than from the basolateral surface. A. (Top) Schematic view of transwell antigen processing assay. Because HLA-DR expression and antigen presentation is restricted to the basolateral surface (Figs. 1-3), the T84 HLA-DR4 transfectants are plated with their basolateral surface exposed to the top chamber. The polarized, electrically resistant $\left(>1,000 \mathrm{ohm} \mathrm{\textrm {cm } ^ { 2 } )}\right.$ monolayers were then pulsed for $4 \mathrm{~h}$ with antigen from the apical surface (bottom chamber) or basolateral surface (top chamber), after which the antigen was removed and $\mathrm{T}$ cells were added always to the top chamber as in Fig. 3. (Bottom) IL-2 production from a TT-specific, HLA-DRB1*0401-restricted T cell hybridoma after an $80 \mu \mathrm{g} / \mathrm{ml}$ TT pulse, wash, and 20-h co-cultivation of the T cells with the T84 monolayers. $B$. Antigen dose-response curve after exposure to the apical (open triangles) or basolateral surface (open squares) as outlined above. pression of CIITA was not "dominant" to the effects seen with $\gamma$-IFN in altering barrier function. The pattern of TER elevation after plating of the cells on transwells and the kinetics and character of the response to $\gamma$-IFN were identical in the wild- type T84 cells and the CIITA transfectants (data not shown). Moreover, as seen in Fig. 1, there was no discernible difference in morphology, ZO-1 staining, or class II localization in the CIITA transfectants compared to the HLA-DR transfectants. 
A

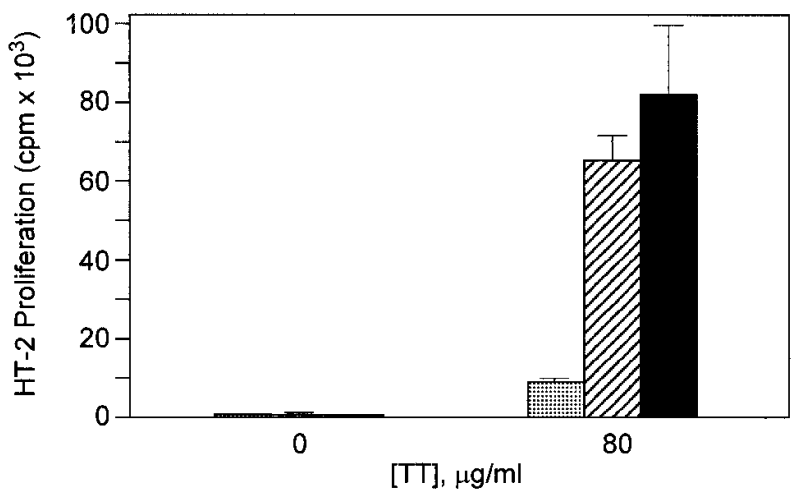

C

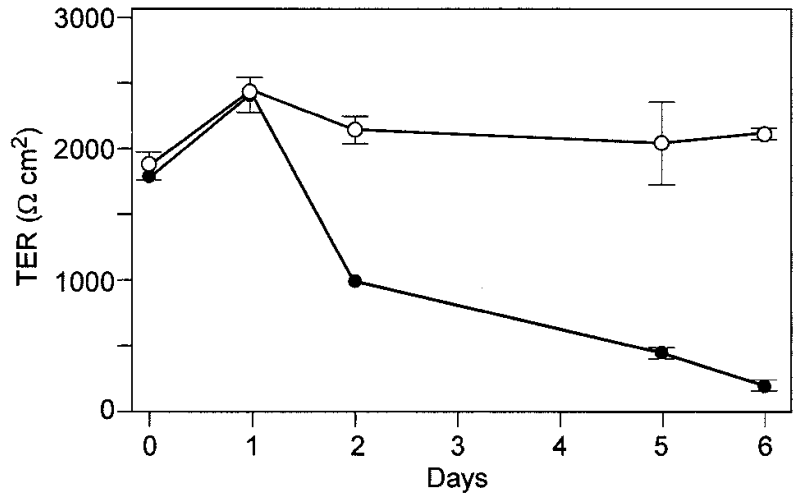

B
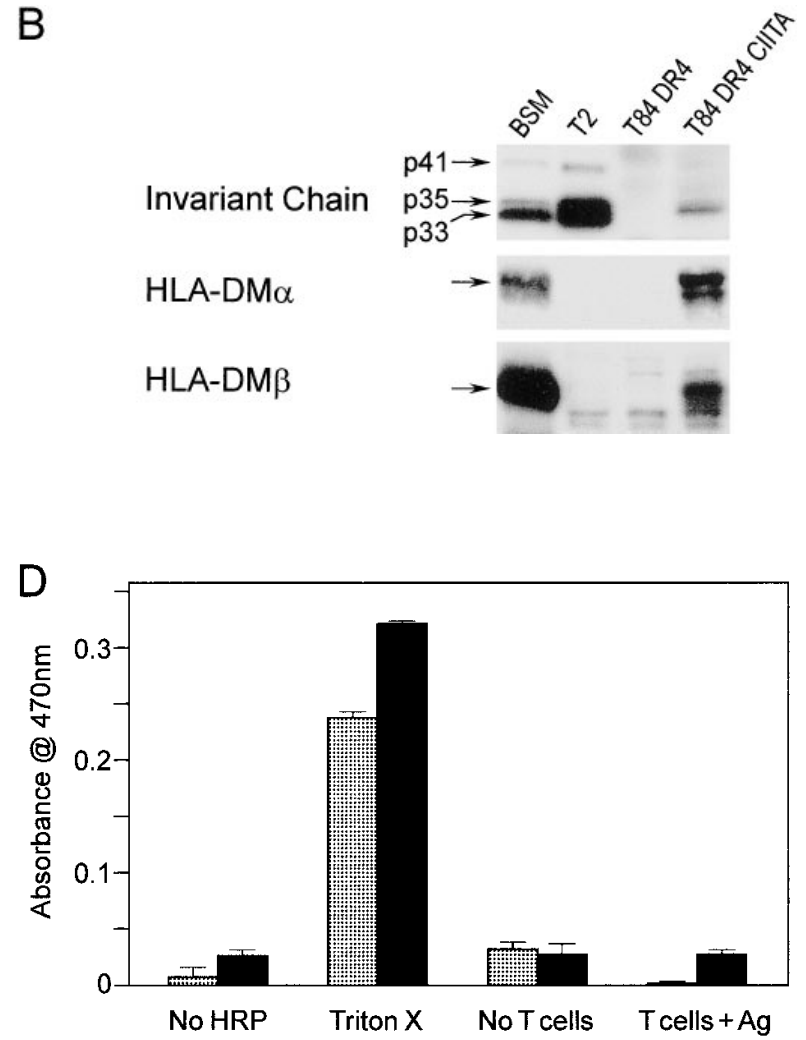

Figure 5. The overexpression of the class II transactivator CIITA in T84 HLA-DR transfectants results in efficient antigen processing without affecting barrier function. ( $A$ ) IL-2 production by the TT-specific, HLA-DRB $1 * 0401$-specific hybridoma stimulated by T84 HLA-DRB1*0401 transfectants in the presence (right) or absence (left) of $80 \mu \mathrm{g} / \mathrm{ml}$ TT. Assays were performed on 96-well flat bottom plates (not on transwells) as described previously. T84 cells used were T84 HLA-DRB1*0401 (stippled bars), T84 HLA-DRB1*0401 pulsed with $\gamma$-IFN for $48 \mathrm{~h}$ before addition of TT (striped bars), and T84 HLA-DRB1*0401/CIITA transfectants in the absence of $\gamma$-IFN (filled bars) (B) Immunoblot analysis using antibodies specific for Ii, HLA-DM $\alpha$, or HLA-DM $\beta$ in the cells listed. $(C)$ Overexpression of CIITA does not impair the ability of T84 cells to develop a high TER. Both curves represent TER data from T84 cells transfected with and expressing CIITA. Media from both the top and bottom chambers were changed daily with (closed circles) or without (open circles) the addition of $500 \mu / \mathrm{ml} \gamma$-IFN to the basolateral surface of the cell. (D) Overexpression of CIITA does not result in the paracellular transport of proteins across the T84 monolayer. Bulk protein transport was assessed using intact HRP as described. To ensure transport was not affected by the addition of the Tlymphocytes to the monolayer during the processing assays, the HRP assays were done immediately after co-cultivation of the T84 monolayers with $100 \times 10^{3} \mathrm{~T}$ cells for $24 \mathrm{~h}$ in the absence ( $T$ cells) or presence ( $T$ cells $+a g$ ) of antigen. The respective cells used were as labeled in $A$.

The intact barrier function of the T84 cells overexpressing CIITA was further verified by their inability to allow passage of intact HRP (Fig. 5 D). The addition and 24-h co-culture of antigen and antigen-specific, HLA-DRB1*0401-restricted T cell hybridomas to either the T84 DR4 or T84 DR4 CIITA transfectants did not result in any transport of HRP across the monolayer (5 D, "T cells $+\mathrm{Ag}$ "), demonstrating that the monolayers restricted passage of protein during the typical course of the antigen-processing experiments. Hence, overexpression of CIITA resulted in efficient HLA class II antigen processing, but had no apparent effect on barrier function in T84 cells. These results demonstrate that $\gamma$-IFN-induced changes in APC activity can be dissociated at a molecular level from the barrier-disrupting activity.

The overexpression of CIITA facilitates HLA class II antigen processing from the basolateral surface of polarized T84 monolayers. Next we assessed the ability of the T84 HLADRB1*0401/CIITA transfectants to process intact protein antigen in the polarized processing assays. Note that increased class II expression in the CIITA transfectants (compared to the T84 DR4 transfectants alone) corresponds to that from the endogenous HLA-DRB1*0101 allele and does not interfere with the functional studies detailed using $\mathrm{T}$ cells that are restricted to the transfected HLA-DRB1*0401 allele. In contrast to the restricted ability of the HLA-DR transfectants to initiate processing of intact TT only at the apical surface, the T84 HLA-DR4/CIITA transfectants could initiate processing from either the apical or basolateral surface (Fig. 6). The antigen dose response curves done under identical conditions consistently reveal that the apical processing in the DR4/ CIITA transfectants is more efficient at low antigen doses than the basolateral processing in the DR4/CIITA transfectants, or the apical processing in the DR4 transfectants alone (Figs. $4 B$ and 6). The data indicate that in the presence of CIITA expression (mirroring the response of $\gamma$-IFN facilitating efficient antigen processing), the highly restricted polar initiation of processing is no longer evident, and both polar surfaces can initiate antigen processing. In both instances, the presentation to $\mathrm{CD}^{+} \mathrm{T}$ cells remains restricted to the basolateral surface of the cell. 


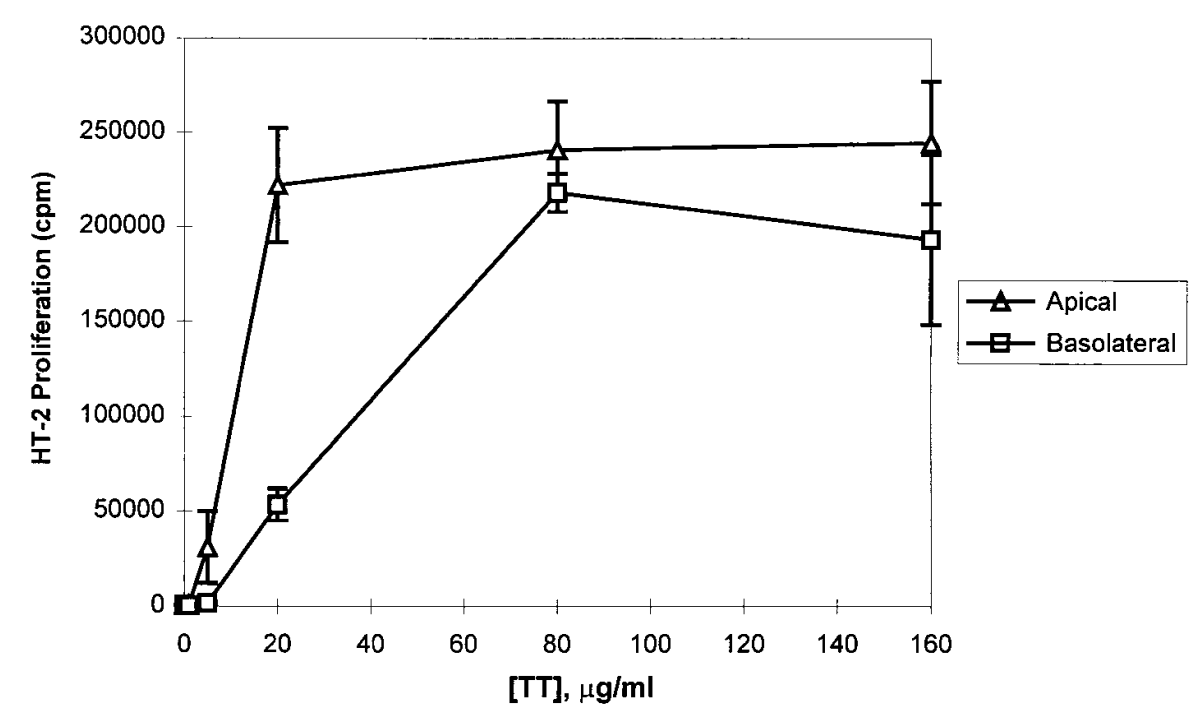

Figure 6. Expression of CIITA in the T84 DR4 transfectants restores the ability of the cells to efficiently process intact TT from the basolateral surface. T84 HLADRB1*0401/CIITA transfectants were used in polar antigen-processing assays in a manner identical to that outlined for the T84 DR4 transfectants in Fig. 4. As previously, antigen presentation occurs exclusively at the basolateral surface, and "apical" and "basolateral" correspond to the surface of the cell exposed to intact TT. Shown are antigen dose-response curves after 4-h exposure of intact antigen (TT) from the apical (open triangles) or basolateral (open squares) surfaces. By flow cytometry using an HLA-DR4-specific $\mathrm{mAb}$, the surface expression of HLADRB1*0401 in the T84 DRB1*0401 and T84 DRB1*0401/CIITA transfectants was indistinguishable (data not shown).
Class II processing initiated from both the apical and basolateral surface requires endosomal acidification but only the apical processing is inhibited by disruption of the actin-based cytoskeleton. We next compared the sensitivity of the apical processing in the T84 DR4 transfectants and the apical and basolateral processing in the T84 DR4/CIITA transfectants to several drugs known to inhibit endocytosis or intracellular trafficking events involved in class II processing to investigate the class II pathways from the distinct polarized surfaces. Based on the data obtained from the TT dose response curves, all drug inhibition experiments were performed at a TT concentration of $80 \mu \mathrm{g} / \mathrm{ml}$. The drug concentrations used were determined to be noncytopathic by light microscopy, and TER was checked at the conclusion of the experiment, and although reduced, was found to be $>300 \mathrm{ohms} \mathrm{cm}^{2}$ at the concentrations and exposure times indicated.

Cytochalasin D interferes with the function of actin-containing microfilaments and has been shown to selectively inhibit apical endocytosis in Madine-Darby canine kidney (MDCK) cells $(28,29)$. Analogously, cytochalasin D selectively inhibited the antigen processing of apically added antigen in a dose-dependent manner (Fig. 7). In contrast, processing from the basolateral surface was unaffected by cytochalasin D. The macrolide antibiotic bafilomycin A1, which inhibits the vacuolar H1 ATPase resulting in inhibition of endosomal acidification (30), showed a dose-dependent inhibition of class II antigen processing from both the apical and basolateral surfaces, although the inhibition at low concentration for the apical processing in the DR4 and DR4/CIITA transfectants was less than for the basolateral processing.

Stimulation of different human T cell clones after class II antigen processing initiated from the apical or basolateral surface of IECs. To determine whether the polarized class II pathways might result in the stimulation of different subsets of $\mathrm{T}$ lymphocytes, we tested the responsiveness of several $\mathrm{CD}^{+}$, TT-specific, HLA-DRB1*0401-restricted human T cell clones for their ability to proliferate against T84 DR4/CIITA transfectants exposed to intact TT from their apical or basolateral surface. In previous studies, we demonstrated that T84 HLADR transfectants could be used as efficient APCs for human T cell clones (14). For the majority of clones studied, pretreatment of the T84 HLA-DR transfectants with $\gamma$-IFN or the directed expression of CIITA in the APC (to induce Ii and HLA-DM) before the addition of antigen was required for optimal $\mathrm{T}$ cell stimulation. In some $\mathrm{T}$ cell clones, however, pretreatment with $\gamma$-IFN or expression of CIITA in the APC actually inhibited the $\mathrm{T}$ cell responses seen, and optimal $\mathrm{T}$ cell proliferation was observed without any manipulation of the T84 HLA-DR transfectants before antigen pulsing and T cell co-cultivation.

Accordingly, we chose two independent $\mathrm{T}$ cell clones for these studies: one clone (designated clone 2) that was enhanced by expression of CIITA in the T84 DR4 transfectant, and another (designated clone 4) in which stimulation was optimal without CIITA expression in the APC. The clonality of these cells was confirmed using RT-PCR and V $\alpha$ - and V $\beta$-specific primers (see Methods section). When assayed using polarized T84 transfectants on transwells, these two clones showed distinct patterns of responsiveness to T84 DR4/CIITA transfectants that depended on which side (i.e., apical or basolateral) antigen was added to the T84 cells. As seen in Fig. 8, clone 2 was stimulated to proliferate by T84 DR4/CIITA cells that processed antigen from the basolateral surface but not from identical cells exposed to antigen from the apical surface. In marked contrast, clone 4 proliferated more vigorously against T84 DR4/CIITA cells that processed antigen from the apical rather than from the basolateral surface. Although the precise peptides recognized by these individual $\mathrm{T}$ cell clones are not known, these data suggest that the same cell exposed to an identical antigen in a polarized context may result in the stimulation of distinct (but potentially overlapping) subsets of T cells.

\section{Discussion}

IECs exist in a highly polarized anatomical context, with high concentrations of dietary and bacterial antigens at the mucosal (apical) surfaces and high concentrations of lymphoid cells at the basolateral surface. HLA class II expression is polarized in 

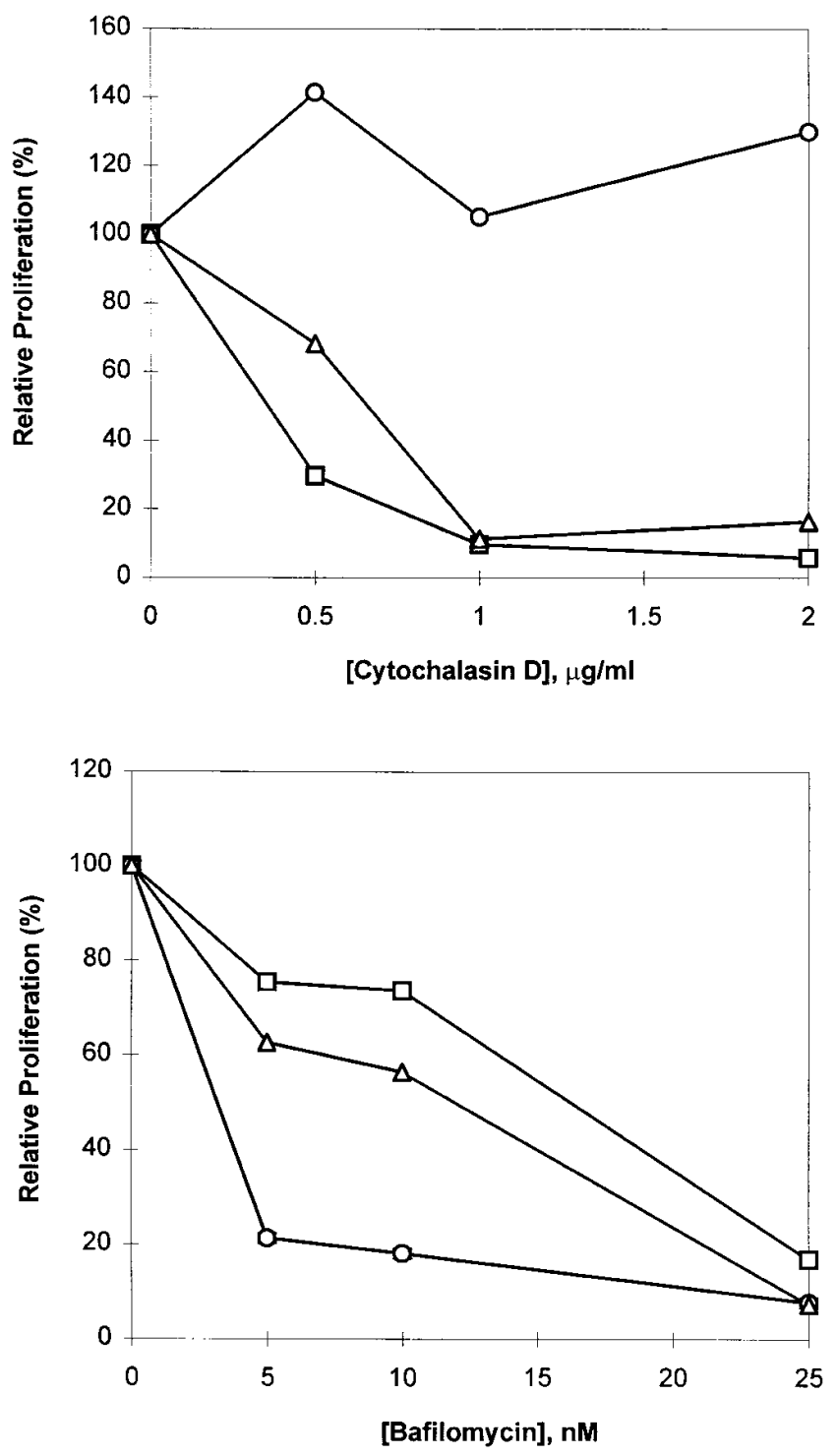

Figure 7. Drug inhibition of class II processing from the apical and basolateral surfaces of T84 transfectants. T84 transfectants were treated with drug for $1 \mathrm{~h}$ at $37^{\circ} \mathrm{C}$ before addition of antigen and throughout antigen pulse. Processing of intact TT at $80 \mu \mathrm{g} / \mathrm{ml}$ was performed in an identical manner to that shown in Figs. 4 and 6. Shown are data from apical processing in the T84 DR4 transfectants (open triangles), apical (open squares), and basolateral (open circles) processing in the T84 DR4 CIITA transfectants. Percent inhibition refers to the ratio of cpm (with drug) to cpm (without drug) under otherwise identical conditions. Standard errors were $<15 \%$.

these cells, restricted to the basolateral membrane, and we now demonstrate that there is a remarkable functional polarity to the antigen-processing and presentation pathway in these cells.

Using three independent approaches-confocal microscopy, selective surface biotinylation, and HLA class II-mediated peptide presentation to antigen-specific T cells-we demonstrate that the surface expression of HLA class II expression in polarized intestinal epithelial cells is restricted to the basolateral surface. These data are consistent with the pattern of surface expression of MHC class II antigens in the human (15,
31) and rat (17) intestinal epithelium seen using immunohistochemistry, and, more recently, in MDCK, a polarized kidney epithelial cell line, cells transfected with HLA-DR1 (32). With regard to the precise sequences required for basolateral targeting of class II molecules, several groups have recently shown that sequences within the cytoplasmic domain of the Ii can direct the expression of a chimeric molecule to the basolateral surface of polarized MDCK cells $(32,33)$. The Ii is physically associated with nascent HLA class II molecules, but is progressively trimmed to the CLIP fragment (which does not contain the basolateral targeting sequence) as the nascent class II complex migrates to an acidic, peptide-loading compartment referred to as CIIV (or MIIC) before transport to the cell surface (reviewed in 11 and 12). Hence, the physiological significance of Ii in directing class II molecules to the basolateral surface of polarized cells remains unclear. Our data using T84 cells engineered to express HLA-DR in the absence of Ii clearly reveal that basolateral targeting of class II molecules does not require Ii. These data are in agreement with the findings that class II expression is mostly restricted to the basolateral surface in MDCK cells expressing HLA-DR in the absence of Ii (32). The precise molecular basis of the spatially-restricted pattern of class II expression at the basolateral surface without Ii has not been investigated. Interestingly, the cytoplasmic tail of the $\beta$ chain of class II contains a di-leucine motif that has been implicated in recycling from the cell surface $(34,35)$, endosomal localization (36), and basolateral targeting (36 and reviewed in 37). It is also possible that sequences in the cytoplasmic tail of the $\alpha$ chain of the class II heterodimer, which have also been implicated in recycling of mature class II molecules from the cell surface (35), may contribute to basolateral targeting.

In addition to the restricted expression of HLA class II molecules at the basolateral surface, there was remarkable polarity with regard to the ability of the epithelial cell to process intact antigen with the processing of TT initiated only from the apical surface in T84 cells directed to express HLA-DR molecules in the absence of Ii and HLA-DM. To be able to study the potential effects of $\gamma$-IFN on polarized aspects of class II processing in IEC in the absence of the untoward effects of this cytokine in disrupting the barrier function of T84 monolayers, we directed the overexpression of CIITA (with the concomitant induction of Ii and HLA-DM expression) in the T84 HLA-DR transfectants. We observed that antigen processing was more efficient in the CIITA "co-transfectants" and that, strikingly, both polar surfaces were capable of initiating class II antigen processing.

In this context, several features of the CIITA transfectants are noteworthy. First, in contrast to the report of Siegrist et al., which detailed the inability of melanoma cells overexpressing CIITA to efficiently process intact antigen (38), the overexpression of CIITA in T84 cells was sufficient to confer efficient class II antigen processing that consistently equaled or exceeded that seen after treatment with $\gamma$-IFN. These data suggest that the effect of CIITA is not identical in all "nonprofessional" antigen-presenting cells. IECs, such as T84 cells, may be especially proficient in class II processing in the setting of CIITA expression because they constitutively express high levels of cysteine and aspartyl proteases (14) including cathep$\sin$ S (R. Hershberg and H. Chapman, unpublished data). Second, the directed overexpression of CIITA enhanced antigen processing in T84 cells without a concomitant decrease in bar- 


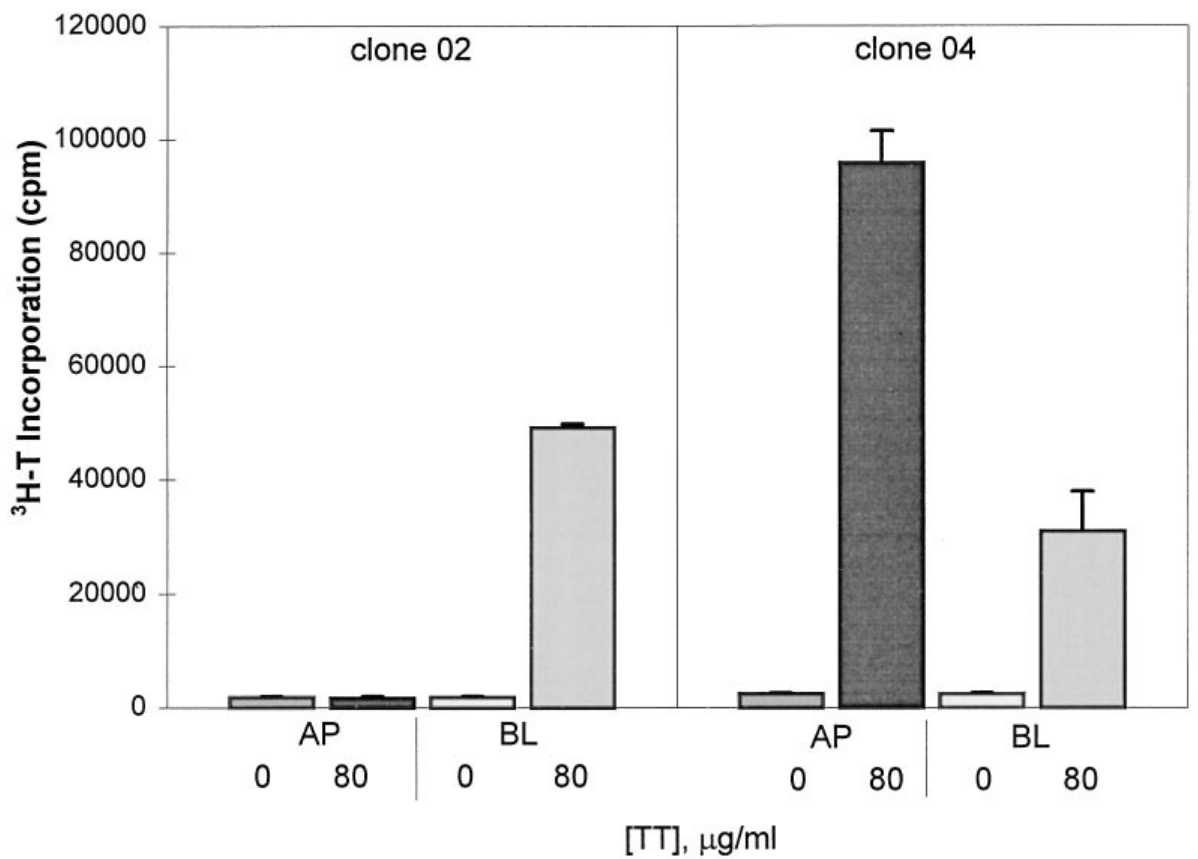

Figure 8. Different human T cell clones are selectively stimulated after class II processing initiated from the apical or basolateral surface with the same antigen. Stimulation of two different TT-specific HLA-DRB1*0401-restricted T cell clones (designated clone 2 and 4, respectively) by T84 DR4 CIITA transfectants on transwells pulsed with $80 \mu \mathrm{g} / \mathrm{ml}$ TT from the apical or basolateral surface, as indicated. After $24 \mathrm{~h}$ of co-culture, the T cell clones were removed from the top chamber of the transwells and cultured in 96-well round bottom plates (without further addition of antigen or APC) for 48 h. $1.0 \mu \mathrm{Ci}^{3}[\mathrm{H}]$ thymidine was present during the last $18 \mathrm{~h}$ of culture, and ${ }^{3}[\mathrm{H}]$ thymidine uptake was measured. All points were done in triplicate and standard error is indicated.

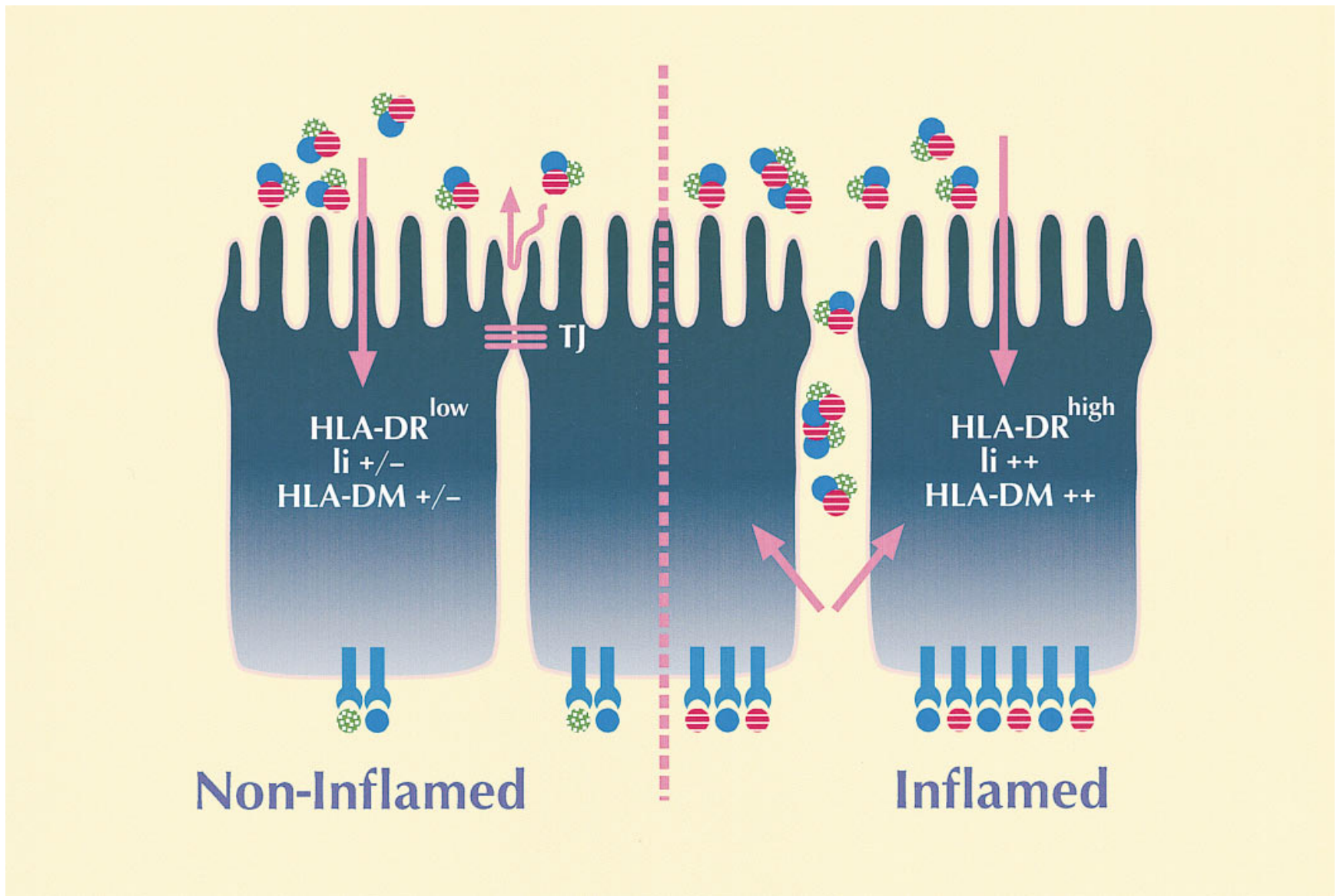

Figure 9. A model for polarized HLA class II antigen processing by IECs. Inflammatory stimuli, such as $\gamma$-IFN, result in the exposure of the basolateral surface to luminal (apical) antigens via "leaky" tight junctions (TJ) concomitant with the induction of HLA-DR, Ii, and HLA-DM. Regardless of the surface of antigen exposure, peptide presentation via class II is restricted to the basolateral surface of the cell. The patterned and filled circles represent distinct peptide epitopes within a given protein antigen revealing nonidentical, but potentially overlapping, HLA-peptide complexes generated from epithelial cells from inflamed or noninflamed mucosa. 
rier function. This demonstrates that the effects of $\gamma$-IFN in the regulation of "physiological" epithelial cell functions, such as tight junction permeability, may be dissociated at the molecular level from its effect on the induced expression of immunologically relevant molecules, such as Ii and HLA-DM.

The polarized trafficking of antigen via HLA class II in epithelial cells highlight the complexity of endosomal structures in polarized epithelial cells, with distinct apical and basolateral structures that communicate somewhat through a "common" endosomal pathway $(39,40)$. Based on the inhibition of both apical and basolateral processing by the proton pump inhibitor bafilomycin, processing of antigen from both polarized surfaces requires transit through an acidic compartment. These data are consistent with several studies detailing the trafficking of nascent and recycled class II through acidic endosomal structures in the presence or absence of Ii $(34,41)$. The selective stimulation of several $\mathrm{CD}^{+} \mathrm{T}$ cell clones depending on the route of antigen uptake suggests that processing from the apical or basolateral surface has the capacity to generate different HLA class II-peptide complexes from the same antigen. This is reminiscent of other reports that the processing and presentation of specific peptide epitopes within the same protein antigen $(34,41)$ or virus particle $(42)$ appear highly dependent on the presence or absence of Ii and/or HLA-DM (reviewed in 43). The data presented here provide the first polarized context for such Ii and HLA-DM independent class II processing events, and are likely to be of physiological significance, given both the high concentration and large number of food and microbial antigens constantly in contact with the intestinal epithelium.

In summary, we identify distinct features of HLA class II processing after exposure of either the apical or basolateral surface to a protein antigen, and a schematic model is presented in Fig. 9. As shown, the spatially restricted pattern of class II expression on the basolateral surface of polarized IECs facilitates the presentation of antigens to T cells within the epithelium and in the underlying lamina propria. This polarized peptide presentation via HLA class II at the basolateral surface occurs whether the intact antigen is internalized and processed from the apical or basolateral surface of the cell. The combined effect of proinflammatory cytokines such as $\gamma$-IFN within the intestinal mucosa in altering barrier function (allowing increased paracellular passage of luminal antigens across the epithelium), coupled with the facilitation of efficient antigen processing and presentation by intestinal epithelial cells, may help to explain the exaggerated and often intractable inflammatory response seen in the intestinal mucosa of patients with inflammatory bowel disease. This may result in the processing and presentation of distinct peptide epitopes from luminal antigens by epithelial cells from inflamed (in contrast to "noninflamed") mucosa. Whether the "sampling" of luminal antigens via apical processing and presentation by class II molecules of certain peptide epitopes by the intestinal epithelium to $\mathrm{CD} 4^{+} \mathrm{T}$ cells in the lamina propria in the noninflamed mucosa contributes to the generation of oral tolerance remains a matter for speculation. Consistent with the data presented here, proinflammatory cytokines are likely to dramatically alter the delicate balance between tolerance and responsiveness in the intestinal mucosa. In this context it is notable that $\gamma$-IFN administration to mice can abrogate the tolerogenic effect of orally administered antigen (44), yet oral tolerance can occur in $\gamma$-IFN-receptor ${ }^{-1-}$ mice (45).

\section{Acknowledgments}

We gratefully acknowledge Linda Wicker and Dennis Zaller (Merck Research Laboratories) for $\mathrm{T}$ cell hybridomas, Jane Buckner and Steve Ziegler (Virginia Mason Research Center) for critical review of the manuscript, Nicky Ducommun for help with preparation of the manuscript, and Mari Hall for expert assistance with preparation of figures.

This work was supported by a First Award from Crohn's and Colitis Foundation of America (R.M. Hershberg); National Institutes of Health (Bethesda, MD) grant AI50902 (J.S. Lee); National Institutes of Health grant AI38913 (G.T. Nepom).

\section{References}

1. Jung, H.C., L. Eckmann, S.-K. Yang, A. Panja, J. Fierer, E. MorzyckaWroblewska, and M.F. Kagnoff. 1995. A distinct array of proinflammatory cytokines is expressed in human colon epithelial cells in response to bacterial invasion. J. Clin. Invest. 95:55-65.

2. Cepek, K.L., S.K. Shaw, C.M. Parker, G.J. Russell, J.S. Morrow, D.L. Rimm, and M.B. Brenner. 1994. Adhesion between epithelial cells and T lymphocytes mediated by E-cadherin and the alpha E beta 7 integrin. Nature. 372: 190-193.

3. Chen, Y., J. Inobe, and H.L. Weiner. 1995. Induction of oral tolerance to myelin basic protein in CD8-depleted mice: both $\mathrm{CD}^{+}{ }^{+}$and $\mathrm{CD} 8^{+}$cells mediate active suppression. J. Immunol. 155:910-916.

4. Garside, P., M. Steel, F.Y. Liew, and A.M. Mowat. 1995. CD4 ${ }^{+}$but not $\mathrm{CD}^{+} \mathrm{T}$ cells are required for the induction of oral tolerance. Int. Immunol. 7 : 501-504.

5. Barone, K.S., S.L. Jain, and J.G. Michael. 1995. Effect of in vivo depletion of $\mathrm{CD}^{+}$and $\mathrm{CD}^{+}$cells on the induction and maintenance of oral tolerance. Cell. Immunol. 163:19-29.

6. Powrie, F. 1995. T cells in inflammatory bowel disease: protective and pathogenic roles. Immunity. 3:171-174.

7. Germain, R.N. 1994. MHC-dependent antigen processing and peptide presentation: providing ligands for T lymphocyte activation. Cell. 76:287-299.

8. Mayer, L., D. Eisenhardt, P. Salomon, W. Bauer, R. Plous, and L. Piccinini. 1991. Expression of class II molecules on intestinal epithelial cells in humans. Differences between normal and inflammatory bowel disease. Gastroenterology. 100:3-12.

9. Bland, P.W., and C.V. Whiting. 1992. Induction of MHC class II gene products in rat intestinal epithelium during graft-versus-host disease and effects on the immune function of the epithelium. Immunology. 75:366-371.

10. Ciclitira, P.J., J.M. Nelufer, H.J. Ellis, and D.J. Evans. 1986. The effect of gluten on HLA-DR in the small intestinal epithelium of patients with Coeliac disease. Clin. Exp. Immunol. 63:101-104.

11. Wolf, P.R., and H.L. Ploegh. 1995. How MHC class II molecules acquire peptide cargo: biosynthesis and trafficking through the endocytic pathway. Annu. Rev. Cell Dev. Biol. 11:267-306.

12. Cresswell, P. 1994. Assembly, transport, and function of MHC class II molecules. Annu. Rev. Immunol. 12:259-293.

13. Kaiserlian, D., K. Vidal, and J.-P. Revillard. 1989. Murine enterocytes can present soluble antigen to specific class II-restricted $\mathrm{CD} 4^{+} \mathrm{T}$ cells. Eur. J. Immunol. 19:1513-1516.

14. Hershberg, R.M., P.E. Framson, D.H. Cho, L.Y. Lee, S. Kovats, J. Beitz, J.S. Blum, and G.T. Nepom. 1997. Intestinal epithelial cells utilize two distinct pathways for HLA class II antigen processing. J. Clin. Invest. 100:204-215.

15. Hirata, I., L.L. Austin, W.H. Blackwell, J.R. Weber, and W.O. Dobbins, III. 1986. Immunoelectron microscopic localization of HLA-DR antigen in control small intestine and colon and in inflammatory bowel disease. Dig. Dis. Sci. 31:1317-1330.

16. Sarles, J., J.P. Gorvel, D. Olive, S. Maroux, C. Mawas, and F. Giraud. 1987. Subcellular localization of class I (A,B,C) and class II (DR and DQ) MHC antigens in jejunal epithelium of children with coelic disease. J. Pediatr. Gastroenterol. Nutr. 6:51-56.

17. Mayrhofer, G., and L.D. Spargo. 1990. Distribution of class II major histocompatibility antigens in enterocytes of the rat jejunum and their association with organelles of the endocytic pathway. Immunology. 70:11-19.

18. Madara, J.L., and J. Stafford. 1989. Interferon- $\gamma$ directly affects barrier function of cultured intestinal epithelial monolayers. J. Clin. Invest. 83:724-727.

19. Bradley, M.B., J.M. Fernandez, G. Ungers, T. Diaz-Barrientos, V. Steimle, B. Mach, R. O'Reilly, and J.S. Lee. 1997. Correction of defective expression in MHC class II deficiency (bare lymphocyte syndrome) cells by retroviral transduction of CIITA. J. Immunol. 159:1086-1095.

20. Hughson, E.J., and R.P. Hirt. 1996. Assessment of cell polarity. In Epithelial Cell Culture. A.J. Shaw, editor. IRL Press, Oxford, UK. 37-66.

21. Planchon, S.M., C.A. Martins, R.L. Guerrant, and J.K. Roche. 1994. Regulation of intestinal epithelial barrier function by TGF- $\beta$ 1. Evidence for its 
role in abrogating the effect of a T cell cytokine. J. Immunol. 153:5730-5739.

22. Woods, A., H.Y. Chen, M.E. Trumbauer, A. Sirotina, R. Cummings, and D.M. Zaller. 1994. Human major histocompatibility complex class IIrestricted T cell responses in transgenic mice. J. Exp. Med. 180:173-181.

23. Genevée, C., A. Diu, J. Nierat, A. Caignard, P.-Y. Dietrich, L. Ferradini, S. Roman-Roman, F. Triebel, and T. Hercend. 1992. An experimentally validated panel of subfamily-specific oligonucleotide primers (Va1-w29/Vb1w24) for the study of human $\mathrm{T}$ cell receptor variable $\mathrm{V}$ gene segment usage by polymerase chain reaction. Eur. J. Immunol. 22:1261-1269.

24. Colgan, S.P., C.A. Parkos, J.B. Matthews, L. D’Andrea, C.S. Awtrey, A.H. Lichtman, C. Delp-Archer, and J.L. Madara. 1994. Interferon- $\gamma$ induces a cell surface phenotype switch on T84 intestinal epithelial cells. Am. J. Physiol. 36:C402-C410.

25. Gottardi, C.J., L.A. Dunbar, and M.J. Caplan. 1995. Biotinylation and assessment of membrane polarity: caveats and methodological concerns. Am.J. Physiol. 268:F285-F295.

26. Strohmeier, G.R., W.I. Lencer, T.W. Patapoff, L.F. Thompson, S.L. Carlson, S.J. Moe, D.K. Carnes, R.J. Mrsny, and J.L. Madara. 1997. Surface expression, polarization, and functional significance of CD73 in human intestinal epithelia. J. Clin. Invest. 99:2588-2601.

27. Chang, C.-H., and R.A. Flavell. 1995. Class II transactivator regulates the expression of multiple genes involved in antigen presentation. J. Exp. Med. 181:765-767.

28. Gottlieb, T.A., I.E. Ivanov, M. Adesnik, and D.D. Sabatini. 1993. Actin microfilaments play a critical role in endocytosis at the apical but not the basolateral surface of polarized epithelial cells. J. Cell Biol. 120:695-710.

29. Jackman, M.R., W. Shurety, J.A. Ellis, and J.P. Luzio. 1994. Inhibition of apical but not basolateral endocytosis of ricin and folate in Caco-2 cells by cytochalasin D. J. Cell Sci. 107:2547-2556.

30. Lencer, W.I., G. Strohmeier, S. Moe, S.L. Carlson, C.T. Constable, and J.L. Madara. 1995. Signal transduction by cholera toxin: processing in vesicular compartments does not require acidification. Am. J. Physiol. 269:G548-G557.

31. Pociot, F., A.G. Wilson, J. Nerup, and G.W. Duff. 1993. No independent association between a tumor necrosis factor- $\alpha$ promoter region polymorphism and insulin-dependent diabetes mellitus. Eur. J. Immunol. 23:3050-3053.

32. Simonsen, A., E. Stang, B. Bremnes, M. Roe, K. Prydz, and O. Bakke. 1997. Sorting of MHC class II molecules and the associated invariant chain (li) in polarized MDCK cells. J. Cell Sci. 110:597-609.
33. Odorizzi, G., and I.S. Trowbridge. 1997. Structural requirements for major histocompatibility complex class II invariant chain trafficking in polarized Madin-Darby canine kidney cells. J. Biol. Chem. 272:11757-11762.

34. Zhong, G., P. Romagnoli, and R.N. Germain. 1997. Related leucinebased cytoplasmic targeting signals in invariant chain and major histocompatibility complex class II molecules control endocytic presentation of distinct determinants in a single protein. J. Exp. Med.185:429-438.

35. Pinet, V., M. Vergelli, R. Martin, O. Bakke, and E.O. Long. 1995. Antigen presentation mediated by recycling of surface HLA-DR molecules. Nature 375:603-604.

36. Hunziker, W., and C. Fumey. 1994. A di-leucine motif mediates endocytosis and basolateral sorting of macrophage IgG Fc receptors in MDCK cells. EMBO (Eur. Mol. Biol. Organ.) J. 13:2963-2969.

37. Mellman, I. 1995. Molecular sorting of membrane proteins in polarized and nonpolarized cells. Cold Spring Harbor Symp. Quant. Biol. LX:745-752.

38. Siegrist, C.A., E. Martinez-Soria, I. Kern, and B. Mach. 1995. A novel antigen-processing-defective phenotype in major histocompatibility complex class II-positive CIITA transfectants is corrected by interferon- $\gamma$. J. Exp. Med. 182:1793-1799.

39. Knight, A., E. Hughson, C.R. Hopkins, and D.F. Cutler. 1995. Membrane protein trafficking through the common apical endosome compartment of polarized caco-2 cells. Mol. Biol. Cell. 6:597-610.

40. Odorizzi, G., A. Pearse, D. Domingo, I.S. Trowbridge, and C.R. Hopkins. 1996. Apical and basolateral endosomes of MDCK cells are interconnected and contain a polarized sorting mechanism. J. Cell Biol. 135:139-152.

41. Momburg, F., S. Fuchs, J. Drexler, R. Busch, M. Post, G.J. Hammerling, and L. Adorini. 1993. Epitope-specific enhancement of antigen presentation by invariant chain. J. Exp. Med. 178:1453-1458.

42. Pinet, V., M.S. Malnati, and E.O. Long. 1994. Two processing pathways for the MHC class II-restricted presentation of exogenous influenza virus antigen. J. Immunol. 152:4852-4860.

43. Ceman, S., and A.J. Sant. 1995. The function of invariant chain in class II-restricted antigen presentation. Semin. Immunol. 7:373-387.

44. Zhang, Z., and J.G. Michael. 1990. Orally inducible immune unresponsiveness is abrogated by IFN- $\gamma$ treatment. J. Immunol. 144:4163-4165.

45. Kjerrulf, M., D. Grdic, L. Ekman, K. Schon, M. Vajdy, and N.Y. Lycke. 1997. Interferon- $\gamma$ receptor-deficient mice exhibit impaired gut mucosal immune responses but intact oral tolerance. Immunology. 92:60-68. 